\title{
Crustal Magnetic Anomalies in the Antarctic Region Detected by MAGSAT
}

\author{
Jun TAKenaKA $^{1 *}$, Masahisa Yanagisawa ${ }^{2}$, Ryoichi FuJil ${ }^{3}$, and Kazuo ShibuYA ${ }^{3}$ \\ ${ }^{1}$ Department of Earth Science, Faculty of Science, Chiba University, Chiba 260, Japan \\ ${ }^{2}$ Institute of Space and Astronautical Science, Sagamihara-shi, Kanagawa 229, Japan \\ ${ }^{3}$ National Institute of Polar Research, Itabashi-ku, Tokyo 173, Japan
}

(Received June 25, 1990; Revised February 15, 1991)

\begin{abstract}
Crustal magnetic anomalies in the Antarctic region were studied with the MAGSAT CHRONFIN data of 1790 passes.

The GSFC(12/83) model was used to reduce the earth's core field to estimate the
\end{abstract} residual magnetic field. Obtained residual intensity data in the geomagnetic coordinates were averaged over 1 hour magnetic local time (MLT) and $1^{\circ}$ invariant latitude, and then grouped by taking the planetary magnetic activity index $\left(K_{\mathrm{p}}\right)$ as a parameter to derive the Mean Polar Disturbance Fields (MPDFs).

The obtained MPDF for $K_{\mathrm{p}}=2_{0}$, for example, amounts to $50 \mathrm{nT}$ at $85^{\circ} \mathrm{S}$ and decreases monotonically toward lower latitudes on the dawnside. On the duskside, the MPDF takes a small value of $10 \mathrm{nT}$ at $85^{\circ} \mathrm{S}$, decreases to a negative peak of $-30 \mathrm{nT}$ at $78^{\circ} \mathrm{S}$, recovers to a smaller positive peak of $20 \mathrm{nT}$ at $62^{\circ} \mathrm{S}$, and then decreases to zero at further lower latitudes. These characteristic features of the MPDF are attributable to the external fields produced by $S_{\mathrm{q}}^{\mathrm{p}}$ currents with occasional eastward electrojet in the ionosphere, which are superimposed by the magnetic field due to the westward ring current in the magnetosphere.

The MPDFs for $K_{\mathrm{p}}$ values from $0_{0}$ to $2_{0}$ were subtracted from the residual intensity data, and the resultant data were averaged for $3^{\circ}$ by $3^{\circ}$ in latitudes and longitudes to obtain crustal magnetic anomalies at a mean altitude of $450 \mathrm{~km}$. The anomaly contours at an interval of $2 \mathrm{nT}$ reveal long-wavelength $(\sim 500 \mathrm{~km})$ crustal magnetic anomaly patterns with a clear correspondence to geologic provinces.

The anomalies in the oceanic area are negative for abyssal plains, while they are positive for ridges and plateaus. The tectonically active Scotia Sea microplate region is associated with negative anomalies. Land areas of Antarctica are characterized by three positive anomalies over Enderby Land, Gamburtsev Subglacial Mountains and Wilkes Land. Negative land anomalies are also definitely related to geologic provinces such as Queen Maud Land, Queen Mary Land, etc., but a detailed interpretation of overall magnetic anomaly pattern requires more comprehensive geological and geophysical studies.

\section{Introduction}

The geomagnetic field of the earth consists of three sorts of fields originating respectively from the core, the crust above the Curie isotherm, and the external

*Now at Wakamatsu Weather Station, Japan Meteorological Agency, Aizuwakamatsu-shi, Fukushima 965, Japan. 
disturbance in the ionosphere and magnetosphere. The intensity of these fields at a satellite altitude of about $500 \mathrm{~km}$ is roughly $30000-60000 \mathrm{nT}, 10 \mathrm{nT}$ and $100 \mathrm{nT}$, respectively. Thus the extraction of the field of crustal origin, removing the other two kinds of fields, requires extreme care.

The main field, which is produced by a dynamo process in the core, may be modeled by the spherical harmonics to the degree and order of 13 (LANGEL and ESTES, 1982). The disturbance field varies with time and space, so that an adequate selection of geomagnetically quiet data and an adequate modelling of time- and space-dependent disturbance are required. A conventional technique is to apply a high pass filter to the observed data along each satellite pass. For example, MAYHEW (1979) applied some quadratic functions of invariant latitude as such filters to remove long-wavelength and slowlyvarying field generated by ring currents in the magnetosphere. However, these techniques cannot eliminate short-wavelength and faster-varying field generated by, for example, field-aligned currents. When higher-order analytic functions are applied for removing the short-wavelength $(<1000 \mathrm{~km})$ disturbance field, they may distort or remove to some extent the long-wavelength $(\sim 500 \mathrm{~km})$ crustal magnetic anomalies.

It seems thus necessary to introduce another approach for the correction of disturbance fields. YANAGISAWA and KONO (1985), for example, developed a new method; the Mean Ionospheric Field (MIF) correction. They assumed that the external disturbance field is not dependent on geographic coordinates but entirely on geomagnetic coordinates. They averaged the observed data along many satellite passes in the geomagnetic coordinates. The procedure must cancel the crustal magnetic field, leaving only "Mean Ionospheric Fields". The obtained MIF in turn are subtracted from the original data to obtain the desired crustal magnetic anomalies. The MIF correction technique is ascertained to retain long-wavelength crustal magnetic anomalies and offer information for better geological interpretation in middle latitudes than the high-pass filter techniques. However, direct application of the MIF correction method to the data over the polar regions cannot remove the external disturbance enough to reveal the crustal magnetic anomalies. The disturbance in these regions is larger than that in the middle and low latitudes, and depends strongly on the planetary magnetic activity index $K_{\mathrm{p}}$.

In this article, we extend the MIF correction method to apply it to the observed data over the Antarctic region. The deduced crustal magnetic anomalies are compared with those in other studies, and discussed also in connection with the tectonic features of the Antarctic region.

\section{Data Selection}

MAGSAT (MAGnetic field SATellite) was launched on October 30, 1979 by NASA (National Aeronautics and Space Administration, U.S.A.). During its 8 months' life time (November 1979-June 1980), MAGSAT orbited more than 2500 times and acquired geomagnetic data at an altitude ranging from $352 \mathrm{~km}$ to $561 \mathrm{~km}$. Coverage over Antarctica reached up to $83^{\circ} \mathrm{S}$ because of its orbital inclination $97^{\circ}$. The orbit was nearly in the meridian plane of 6:00 and 18:00 geographic local times.

CHRONFIN tapes, provided by NASA-GSFC (Goddard Space Flight Center), contain all MAGSAT data (eight samples per second for the total intensity of geomagnetic field by a Cesium vapor magnetometer, and sixteen samples per second for 
the vector components by fluxgate magnetometers, and ephemeris information once per minute) (LANGEL et al., 1981).

From CHRONFIN tapes, we compiled MAGANT data set, which contains the total intensity data synthesized from the vector magnetic fields, satellite position in geographic coordinates, associated geomagnetic coordinates, and $K_{\mathrm{p}}$ at an interval of $0.5 \mathrm{~s}$ for the Antarctic region (south of $40^{\circ} \mathrm{S}$ ). In deriving the MAGANT data set, the data of the following cases were discarded, when; (1) the north- or east-component data showed large fluctuations, and (2) $K_{\mathrm{p}}$ indices were greater than $2_{+}$, because these data were suspected to be strongly disturbed by field-aligned currents in the magnetosphere. In our analysis, 1790 satellite passes from November 1, 1979 to May 12, 1980 were selected as shown in Fig. 1. The selected passes cover uniformly the region concerned, giving a spacing denser than $20 \mathrm{~km}$ at $70^{\circ} \mathrm{S}$ latitude and a sampling distance denser than $5 \mathrm{~km}$ along ground tracks.

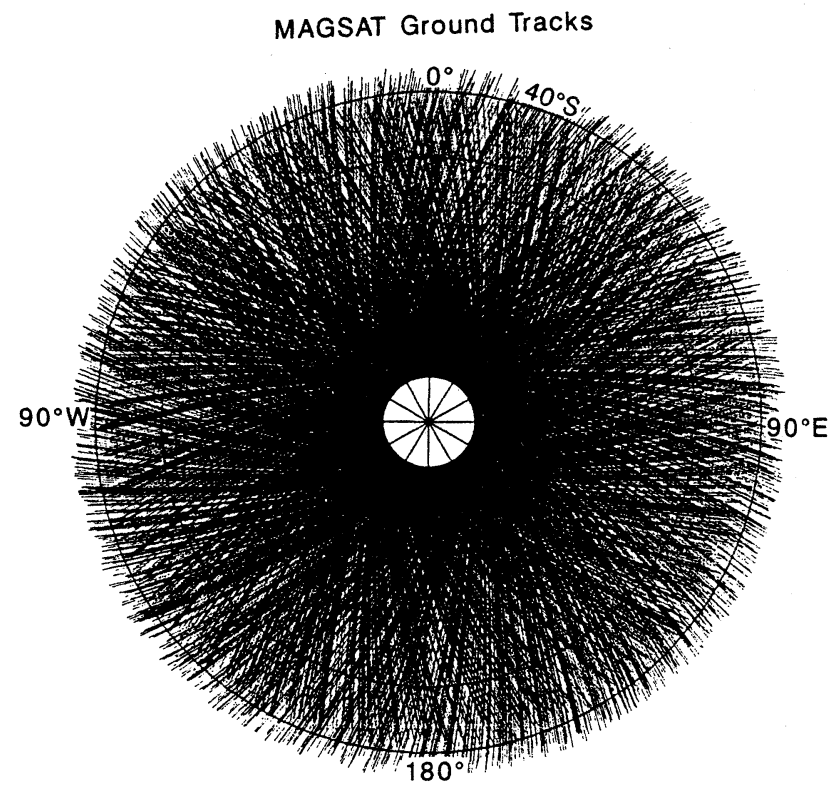

Fig. 1. Superimposed ground tracks of the MAGSAT passes chosen for our analysis over the Antarctic region. There is no coverage to the south of $83^{\circ} \mathrm{S}$.

\section{Derivation of Crustal Magnetic Anomalies}

\subsection{Reduction of the main field}

The GSFC(12/83) model (LANGEL and ESTES, 1985) was adopted to subtract the main field from the synthetic total intensity data. The GSFC(12/83) model includes spherical harmonics up to the order and degree 13, representing most of the core field (LANGEL and ESTES, 1982). Using secular variation terms to the degree and order 10, which are also included in the GSFC(12/83) model, the data were reduced to the values at the epoch of 1980.0. After the GSFC(12/83) total intensity data is subtracted from the 
MAGANT total intensity data, the residual scalar data set, RESANT, can be considered as consisting of the crustal magnetic anomalies and the external disturbance field.

\subsection{Reduction of the external disturbance field}

\subsubsection{Mean Polar Disturbance Field (MPDF)}

We assume that the observed external disturbance field shows small random fluctuations around a mean field, depending only on the geomagnetic coordinates (invariant latitude and MLT) and $K_{\mathrm{p}}$. The validity of this assumption is proven by the fact that the crustal magnetic anomalies derived separately from the dusk and dawn data sets through the MIF correction for mid-latitudes agree with each other at high correlations (YANAGISAWA and KONO, 1984, 1985).

We divided the geomagnetic coordinate plane into sectorial areas; for MLT uniformly into 24 sectors with 1 hour intervals, while for invariant latitude into 50 circular belts with $1^{\circ}$ intervals between $40^{\circ} \mathrm{S}$ and $90^{\circ} \mathrm{S}$. The RESANT data of each $K_{\mathrm{p}}$ index level, $2_{0}$ for example, were distributed into these $1200 \mathrm{bins}$, and were averaged in each bin. Since the crustal magnetic fields are fixed to the geographic coordinates and thus vary randomly in each bin, they are averaged out.

Figure 2 illustrates the mean polar disturbance field (MPDF) thus extracted for $K_{\mathrm{p}}=2_{0}$. There were no data to calculate MPDF in low-latitude bins around noon and midnight because of the sun-synchronous dawn-dusk polar orbit of MAGSAT. Figure 3 shows 6:00-18:00 MLT cross-section of the MPDF. The MPDF (solid curve) on the dawnside shows a monotonic decrease from $50 \mathrm{nT}$ at $85^{\circ} \mathrm{S}$ toward a lower latitude, while on the duskside it takes the small value of $10 \mathrm{nT}$ at $85^{\circ} \mathrm{S}$ and decreases to a negative peak of $-30 \mathrm{nT}$ at $78^{\circ} \mathrm{S}$, recovers to a positive peak of $20 \mathrm{nT}$ at around $62^{\circ} \mathrm{S}$, then decreases with latitude. As shown by broken curves, one-sigma standard deviation is more than 10 $\mathrm{nT}$ at higher latitudes (greater than $70^{\circ} \mathrm{S}$ ), and diminishes within $10 \mathrm{nT}$ for lower latitudes. Since the bin area and the number of observed data become too small to give reliable standard deviations, the MPDFs to the south of $85^{\circ} \mathrm{S}$ are plotted by a dotted curve.

The MPDF is consistent with the fields generated by twin-vortex currents flowing in the polar ionosphere; i.e., $S_{\mathrm{q}}^{\mathrm{p}}$-current, and the superimposing westward equatorial ring (disk) currents in the magnetosphere. This $S_{\mathrm{q}}^{\mathrm{p}}$ current system produces positive magnetic field enhancements on the dawnside and negative ones on the duskside (NAGATA and KoKUBUN, 1962) just like the profile $\left(60^{\circ} \mathrm{S}-85^{\circ} \mathrm{S}\right)$ in Fig. 3. The equatorial ring current generates global southward (upward in the Antarctic region) magnetic fields parallel to the dipole axis, i.e., the Dst field (AKASOFU and CHAPMAN, 1961), which accounts for a monotonic decrease of the MPDF profile $\left(60^{\circ} \mathrm{S}-30^{\circ} \mathrm{S}\right)$ in Fig. 3 on both the dawn and dusk sides. It is worthwhile to mention that these features of the MPDFs are revealed also in the observations by satellite Pogo (LANGEL, 1974a, b).

In the same way as that for $K_{\mathrm{p}}=2_{0}$, the MPDFs for each $K_{\mathrm{p}}$ index level $0_{0}, 0_{+}, 1_{-}, 1_{0}$, $1_{+}$, and 2 - were obtained. The MPDFs for smaller $K_{\mathrm{p}}$ values show smaller standard deviations than those shown in Fig. 3. If we had enough number of data with small $K_{\mathrm{p}}$, e.g. $\leq 1_{+}$, the processings of only such data would suffice. However, the number of data for $K_{\mathrm{p}} \leq 1+$ was insufficient and much less than that of $K_{\mathrm{p}} \leq 2_{0}$. Furthermore it was found that the MPDF profile and its standard deviations changed only slightly between $K_{\mathrm{p}}$ indices of $2_{0}$ and $1_{+}$. We thus adopted the data with $K_{\mathrm{p}}$ ranging from $0_{0}$ to $2_{0}$, that is, all data in RESANT tapes to derive crustal magnetic anomalies. 


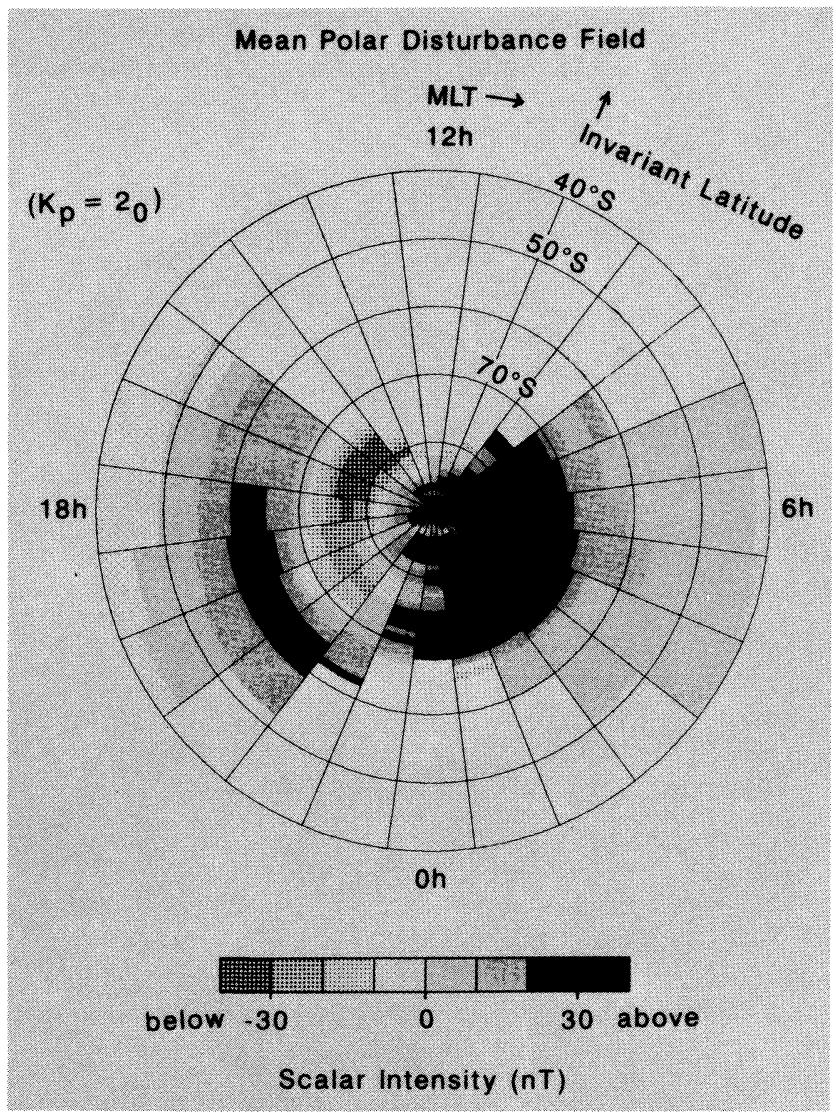

Fig. 2. The Mean Polar Disturbance Field (MPDF) obtained for the data with $K_{\mathrm{p}}=2_{0}$.

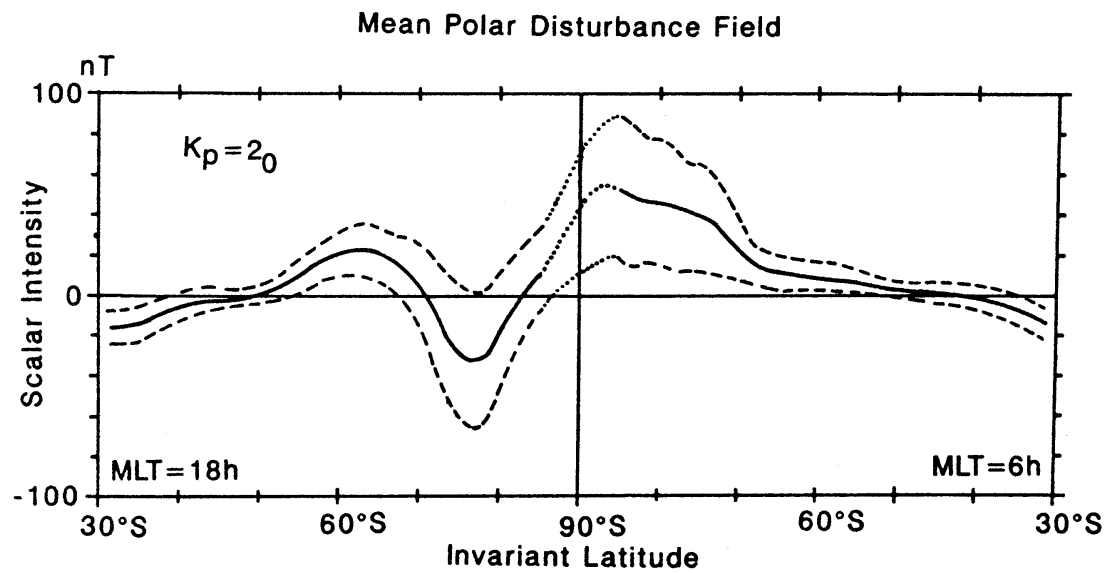

Fig. 3. The MPDF along the sun-synchronous meridian from 6 hour MLT (dawnside) to 18 hour MLT (duskside) for the data with $K_{\mathrm{p}}=2_{0}$. Solid curve indicates the most probable distribution, while the broken curves show one-sigma standard deviations. As for south of $85^{\circ} \mathrm{S}$, dotted curves are plotted because of large uncertainty. 


\section{MAGSAT Crustal Magnetic Anomalies}

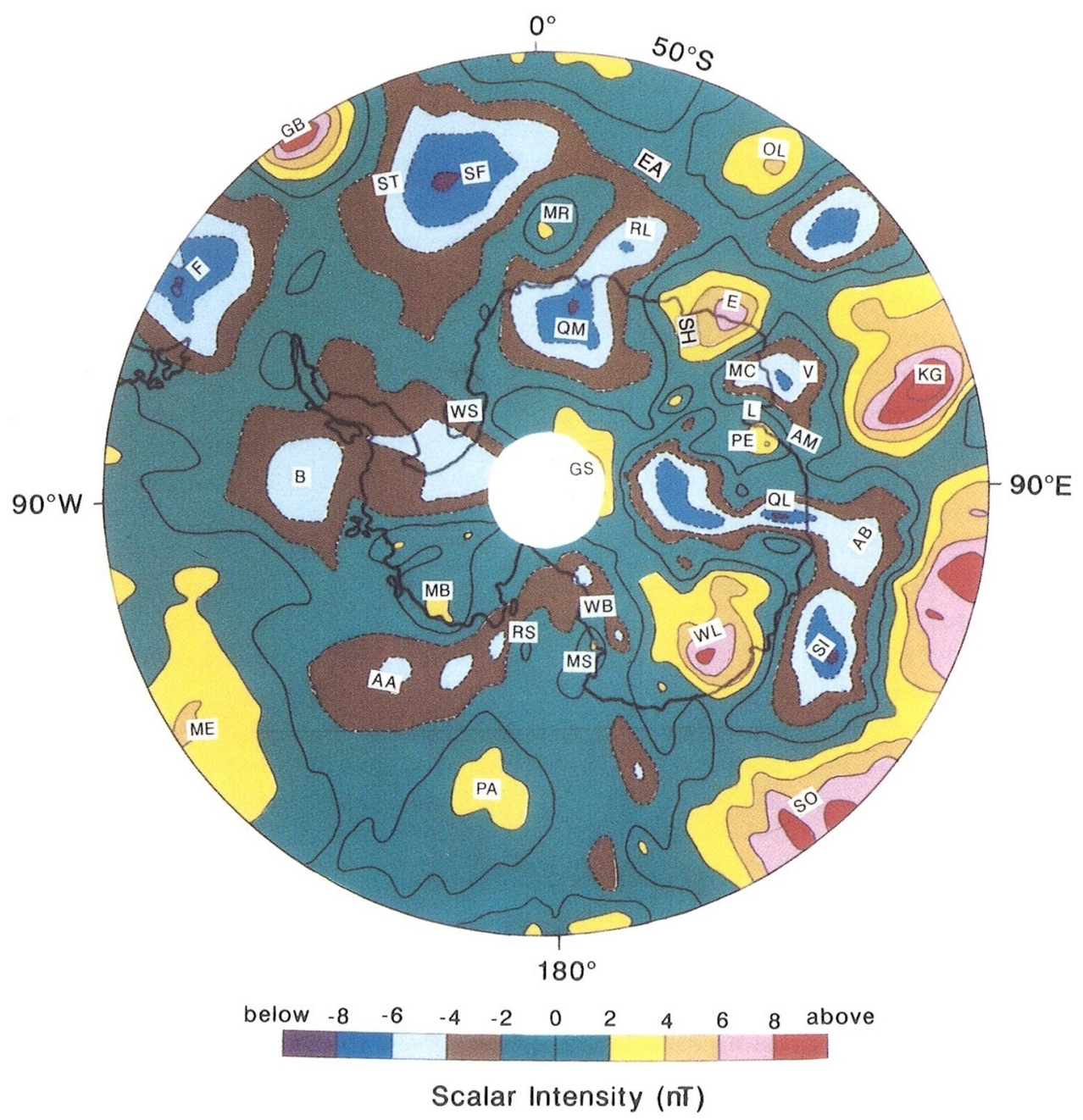

(a)

Fig. 4. (a) Crustal magnetic anomalies in the Antarctic region to the north of $50^{\circ} \mathrm{S}$. Solid contours (warm colours) indicate positive, while broken contours (cold colours) indicate negative. Contour interval is $2 \mathrm{nT}$. (b) Simplified topography of the Antarctic region for comparison with the obtained anomalies. Compiled from Grikurov (1979), Segawn et al. (1984) and Drewry (1983). Hatched area shows bedrock region with elevation above sea level. Shaded area shows region with sea depth below $5000 \mathrm{~m}$. Bathymetric contours are drawn with $1000 \mathrm{~m}$ intervals. See Table 1 for abbreviated region names. 


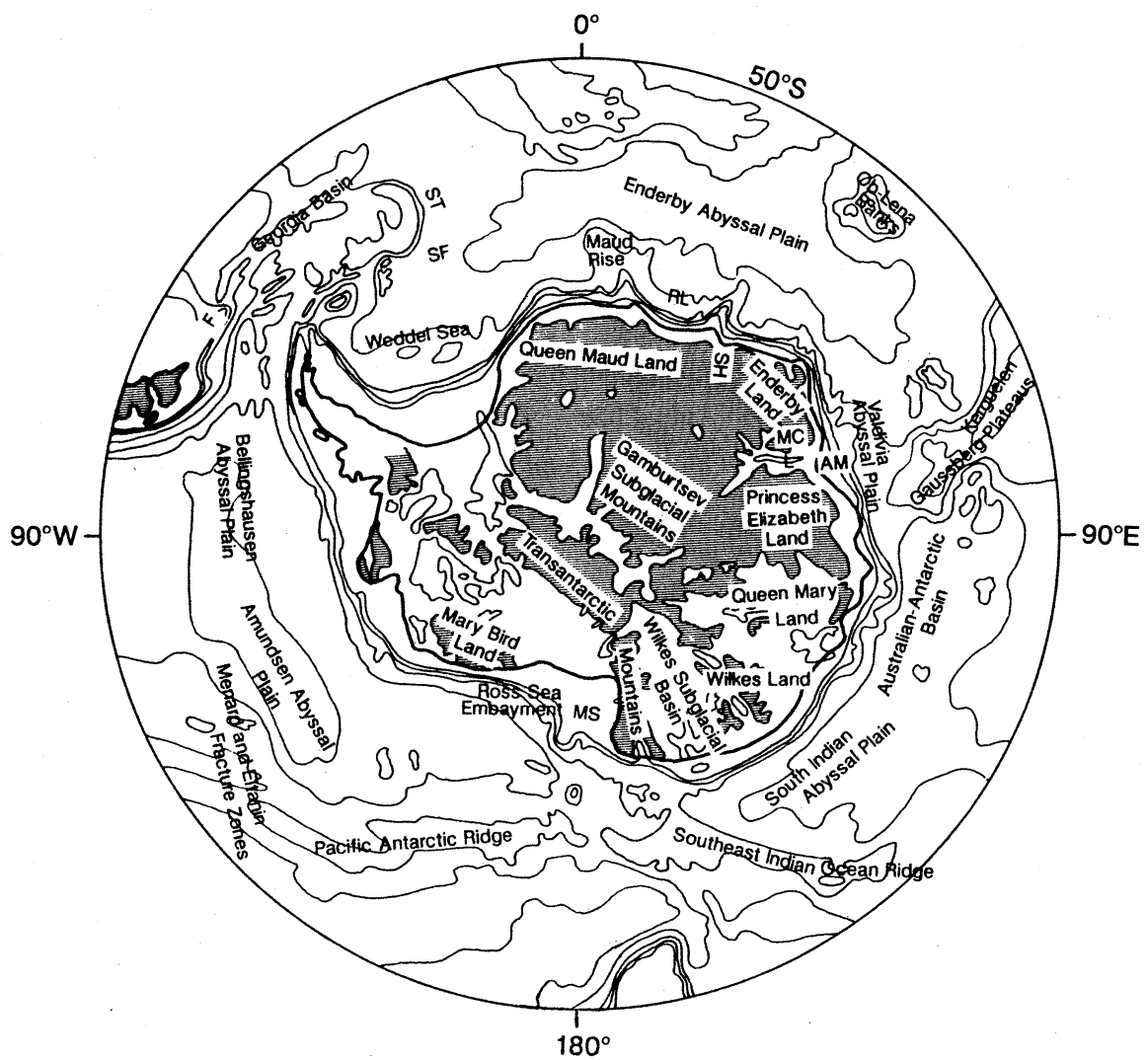

(b)

Fig. 4. (continued).

\subsubsection{Reduction to the crustal magnetic anomalies}

We subtracted the MPDF from the RESANT data for each $K_{\mathrm{p}}$ in the geomagnetic coordinate system, then sorted each data according to geographic coordinates to obtain the ANOMANT data set. The data in the set contain the crustal magnetic anomalies observed at various altitudes $(350 \mathrm{~km} \sim 560 \mathrm{~km})$, contaminated by random external field variations. The ANOMANT data were averaged in each $1^{\circ}$ by $1^{\circ}$ geographic area to cancel out random external fields and obtain anomalies at an average altitude of $450 \mathrm{~km}$.

Figure 4(a) illustrates the obtained crustal magnetic anomalies in a polar stereographic projection chart following Briggs' algorithm (BRIGGS, 1974). Contour interval is $2 \mathrm{nT}$ and solid contours (or warm colours) indicate positive anomalies, while broken contours (or cold colours) indicate negative ones. In Fig. 4(b), the topographic structures and geologic provinces are compiled from GRIKUROV (1979) and SEGAWA et al. (1984) for ocean areas and DREWRY (1983) for land areas, for comparison with the obtained crustal magnetic anomalies. The abbreviation of their names is summarized in Table 1.

\subsubsection{Verification of the MPDF correction}

To demonstrate the effectiveness of external field correction, the coincidence of 
Table 1. Abbreviation of topographic structures and geologic provinces.

\begin{tabular}{ll}
\hline AA & Amundsen Abyssal Plain \\
AB & Australian-Antarctic Basin \\
AM & Amery Ice Shelf \\
B & Bellingshausen Abyssal Plain \\
E & Enderby Land \\
EA & Enderby Abyssal Plain \\
F & Falkland Plateau \\
GB & Georgia Basin \\
GS & Gamburtsev Subglacial Mountains \\
KG & Kerguelen-Gaussberg Plateaus \\
L & Lambert Glacier \\
MB & Mary Bird Land \\
MC & Mac. Robertson Land \\
ME & Menard and Eltanin Fracture Zones \\
MR & Maud Rise \\
MS & McMurdo Sound \\
OL & Ob-Lena Banks \\
PA & Pacific Antarctic Ridge \\
PE & Princess Elizabeth Land \\
QL & Queen Mary Land \\
QM & Queen Maud Land \\
RL & Riiser Larsen Sea \\
RS & Ross Sea Embayment \\
SF & South Sandwich Fracture Zone \\
SH & Shirase Glacier \\
SI & South Indian Abyssal Plain \\
SO & Southeast Indian Ocean Ridge \\
ST & South Sandwich Trench \\
V & Valdivia Abyssal Plain \\
WB & Wilkes Subglacial Basin \\
WL & Wilkes Land \\
WS & Weddel Sea \\
\hline & \\
\hline
\end{tabular}

crustal magnetic anomaly profiles along adjacent satellite passes is examined (e.g. MAYHEW, 1979). However, MPDF corrected data along individual passes still include random external disturbances until they are averaged in a geographic coordinate system, and pass-by-pass comparison is not an effective approach.

For verifying the MPDF correction, we divided the ANOMANT data set into the dawn-data set for dawnside ( 0 h-12 h MLT) and the dusk-data set (12 h-24 h). Since the external disturbance field is asymmetric between the dawn and dusk sides, there would be a disagreement between the anomaly maps derived from these two data sets if the MPDF correction is inappropriate. Figure 5 illustrates the crustal magnetic anomalies from (a) the dawn-data set and (b) the dusk-data set, respectively. The agreement is rather good and we can see positive or negative anomalies at the same location in the two maps. The agreement can surely be made better by applying an appropriate high pass filter to each map. However, the application may "over-damp" the true anomaly feature.

Figure 6 illustrates the distribution of standard errors in the obtained crustal magnetic anomalies. The contouring is made from the distribution of the associated standard error in the averaged magnetic anomaly value at the $1^{\circ}$ by $1^{\circ}$ grid point. Since 6 
(a) Dawn Data

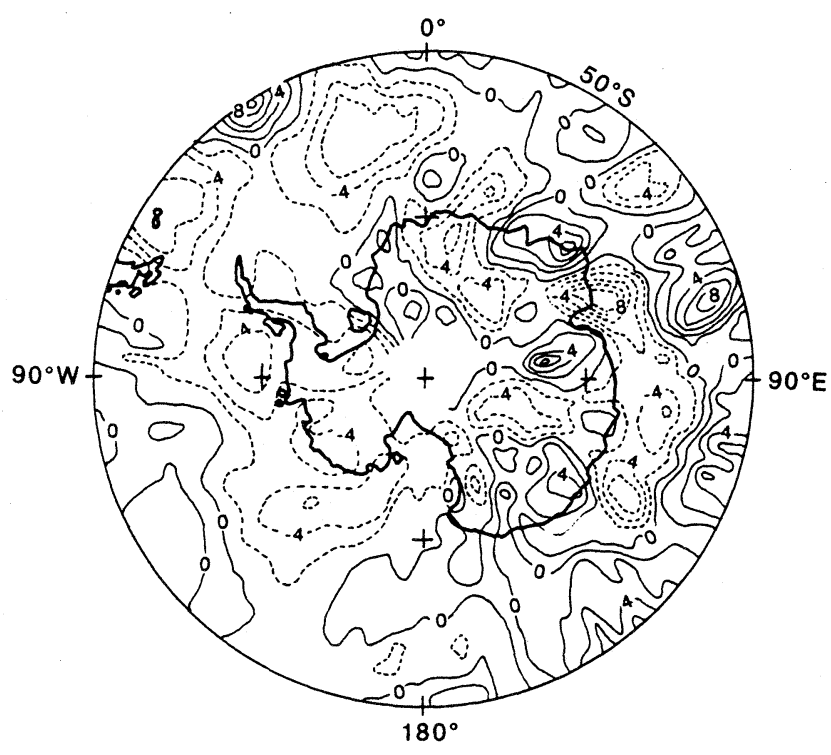

Contour Interval : 2 nT

(b) Dusk Data

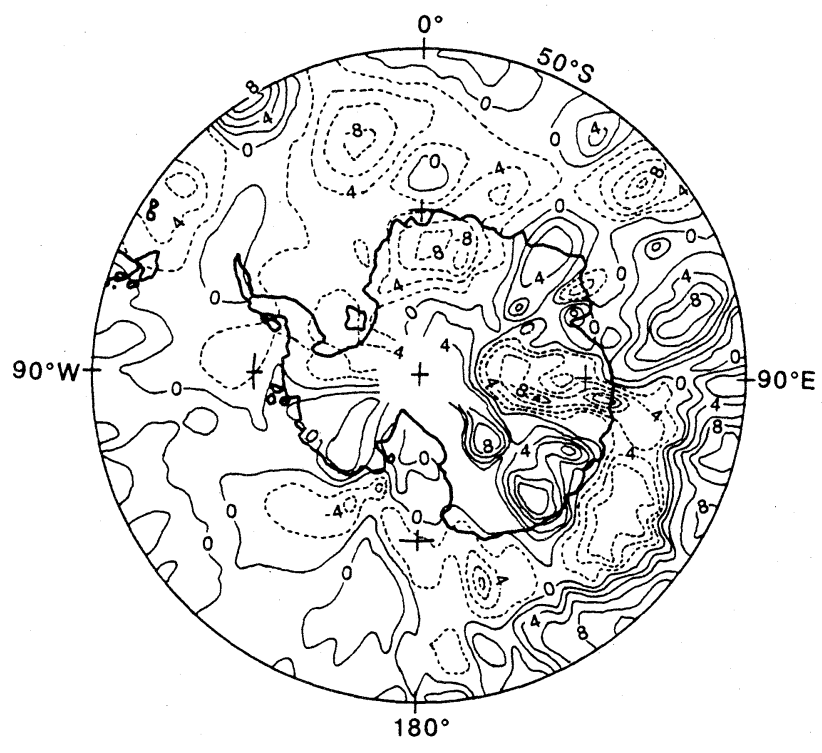

Contour Interval : 2 nT

Fig. 5. Crustal magnetic anomalies derived (a) only from the dawn-data set, and (b) only from the dusk-data set. 


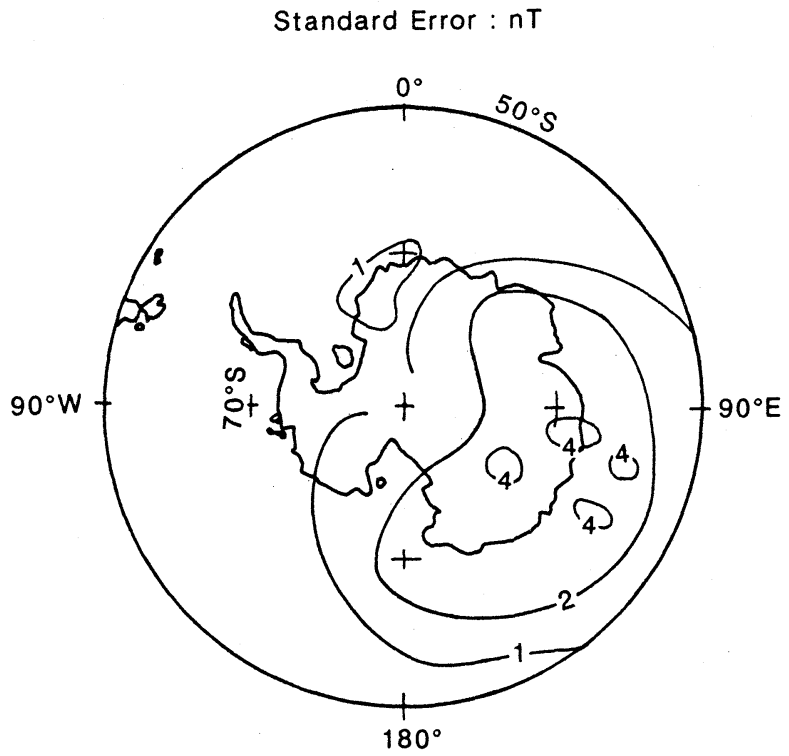

Fig. 6. Estimation of standard errors in the obtained anomalies of the geomagnetic total field intensity.

months' satellite data are used in the estimation of the MPDFs, the obtained crustal magnetic anomalies are affected by the seasonal change of the disturbance field. The above effect is however insignificant because most of the region in Fig. 6 is characterized by standard error values less than $1 \mathrm{nT}$.

The CHRONFIN vector data has a $6 \mathrm{nT}$ uncertainty for each component (LANGEL et al., 1982). Thus the synthetic total intensity has an uncertainty of around $6 \sqrt{3} \sim 10 \mathrm{nT}$. This sensor-related statistical error decreases in proportion to the inverse of the squareroot of the data number as the number of data in each areal element increase. For more than 100 data in the areal element, the above statistical error becomes less than $1 \mathrm{nT}$, which well corresponds to the small standard error values in Fig. 6.

There was some inconsistency between the dawn- and dusk-anomalies (Fig. 5) for the regions within the circle of about $1500 \mathrm{~km}$ diameter with its center at around $\left(73^{\circ} \mathrm{S}\right.$, $110^{\circ} \mathrm{E}$ ), near the geomagnetic pole. The region with standard errors amounting to $4 \mathrm{nT}$ in Fig. 6 is generally within the above circle. Though the averaged crustal magnetic anomaly in Fig. 4(a) from both the dawn- and dusk-data sets may still be contaminated by the possible inaccuracy of the MPDFs, the obtained anomaly pattern seems to have no fictitious distortion, indicating relative anomaly with highs and lows in the whole area.

\section{Features of Obtained Anomalies}

There is a general agreement between the crustal magnetic anomalies obtained by RITZWOLLER and BENTLEY (1983) and those in our study. However, the anomalies reported by RITZWOLLER and BENTLEY (1983) are somewhat reduced in size, probably due to an "over-damping" effect by the pass-by-pass correction method, while our results in Fig. 4(a) retain long-wavelength $(\sim 500 \mathrm{~km})$ anomaly patterns with an enhanced 
correlation among the neighbouring anomalies.

In the circum Antarctic oceans, the major basins and abyssal plains generally have negative anomalies. The anomalies over the Weddel Sea (WS) and the Bellingshausen Abyssal Plain (B) constitute a large negative region covering the eastern half of West Antarctica, including the Antarctic Peninsula and the Ronne Ice Shelf. Other abyssal plains; Riiser Larsen Sea (RL), Amundsen Abyssal Plain (AA), South Indian Abyssal Plain (SI), Australian-Antarctic Basin (AB), all are overlain by negative anomalies.

The ocean ridges and plateaus to the north of the above abyssal plains are generally characterized by zero-to-strong positive anomalies. The Southeast Indian Ocean Ridge (SO) shows remarkable positive anomalies which extend to those over the KerguelenGaussberg Plateaus (KG), covering $90^{\circ}$ from $60^{\circ} \mathrm{E}$ to $150^{\circ} \mathrm{E}$. On the other hand, the Pacific Antarctic Ridge (PA) has less intense anomalies as compared to those over the Southeast Indian Ocean Ridge (SO). The Ob and Lena Banks (OL) are also overlain by distinct positive anomalies, and the northeastern part of the Enderby Abyssal Plain (EA) between the Ob-Lena Banks and the Kerguelen-Gaussberg Plateaus is associated with negative anomalies. Though the positive anomalies over the Maud Rise (MR) are small, it is overlain by relatively higher anomalies than those over the western half of the Enderby Abyssal Plain (EA) and the South Sandwich Fracture Zone (SF).

The anomaly characteristics in the fracture zones and the microplate region become somewhat obscure. The Menard and Eltanin Fracture Zones (ME) are characterized by positive anomalies. The South Sandwich Fracture Zone (SF) and the South Sandwich Trench (ST) are as a whole overlain by large negative anomalies. The Falkland Plateau (F) shows negative, while the Georgia Basin (GB) shows positive, indicating a reversed sense of the anomaly patterns explained hitherto.

Looking at land areas of Antarctica, the most significant feature is a wedge-like pattern by three positive anomalies over Enderby Land (E), Gamburtsev Subglacial Mountains (GS), and Wilkes Land (WL). The Queen Mary Land (QL) negative anomalies are elongated northward by the above blocking two (GS and WL) positive anomalies.

According to MASOLOV et al. (1981), the Lambert Glacier (L) and the Amery Ice Shelf (AM) areas show an evidence of the failed rift zone. Crustal thickness is greatest at the flanks of the Lambert Glacier, where it exceeds $40 \mathrm{~km}$. Under the depressed bedrock relief of the Lambert Glacier, the crust is only $22-25 \mathrm{~km}$ thick. FREY (1982) indicates that such block thinning of the crust results in a relatively negative anomalies over the failed rift zone, and the MAGSAT anomaly map by RITZWOLLER and BENTLEY (1983) gave negative region over the Lambert Glacier and the Amery Ice Shelf region. Contrary to their conclusion, Princess Elizabeth Land (PE) and the Amery Ice Shelf area (AM) are relatively positive in our study and the negative anomalies are coincident with the adjacent Mac. Robertson Land (MC) and the Valdivia Abyssal Plain (V). It seems necessary to examine a reduced-to-pole representation of the MAGSAT anomalies for accurate interpretation of the crustal structure of the regions concerned.

HIROI et al. (1986) and SHIRAISHI (1986) revealed that the metamorphic history of the Yamato-Belgica complex to the west of the Shirase Glacier $(\mathrm{SH})$ was different from that of the eastward Lützow-Holm complex. Submarine topography in the LützowHolm Bay (downstream bay of the Shirase Glacier) shows 300 m systematic depression on the western side of the drowned troughs in the Lützow-Holm Bay (past main-streams of the Shirase Glacier) as compared with the eastern side (MORIWAKI and YosHIDA, 
1983). Airborne magnetic surveys over the Shirase Glacier area indicated strong positive anomalies on the eastern side as compared with the zero-to-weak positive anomalies on the western side of the Shirase Glacier (SHIBUYA and TANAKA, 1983). All ground studies indicated above suggest that the Shirase Glacier $(\mathrm{SH})$ is a geologic boundary between Queen Maud Land (QM) and Enderby Land (E).

The MAGSAT anomalies over Queen Maud Land (QM) are negative and coupled with the north-eastward negative anomalies over the Riiser Larsen Sea (RL). The above two negative anomalies constitute a large north-south trending anomaly covering $20^{\circ}$ from the ocean floor $\left(60^{\circ} \mathrm{S}\right)$ to the inland continent $\left(80^{\circ} \mathrm{S}\right)$. On the other hand, Enderby Land (E) is overlain by strong positive anomalies. The transition zone from positive (east) to negative (west) is somewhat shifted to the west of the Shirase Glacier ( $\mathrm{SH}$ ), which would require reduced-to-pole representation of the anomalies for better geologic interpretation.

There are no remarkable anomalies over the Transantarctic Mountains, and the anomaly pattern is rather different from the results by RITZWOLLER and BENTLEY (1983). In the western half of West Antarctica, positive anomalies are limited to a small patch over Mary Bird Land (MB), while a wedge-shaped negative anomaly runs from the Wilkes Subglacial Basin (WB) to the Ross Sea Embayment (RS), then extending further to the Amundsen Abyssal Plain (AA). There are no noticeable anomalies over the McMurdo Sound (MS), though Ross Island shows a small patch of a relatively positive region.

\section{Discussion and Conclusion}

MAGSAT crustal magnetic anomalies in the Antarctic region are obtained through the MPDF correction method. The obtained MPDFs are consistent with the fields generated by $S_{\mathrm{q}}^{\mathrm{p}}$ current and the equatorial ring current, and well approximate the asymmetric dawn-dusk structure of the external disturbance field. By subtraction of the MPDFs and averaging of the residual data in geographic coordinates, the crustal magnetic anomalies are contoured at an interval of $2 \mathrm{nT}$. They retain rather longwavelength anomaly pattern which, in a conventional pass-by-pass correction method, is likely to be distorted.

It is clarified through this study that the geomagnetic anomalies in the oceanic area are closely connected with the structure of the crust; the magnetic anomalies are negative for basins and abyssal plains, and positive for ridges and plateaus, except those located in the tectonically active Scotia Sea microplate region. If the anomaly pattern is expressible by a combined function of crustal thickness, magnetic susceptibility and heat flow which may distort the Curie isotherm, the basin anomalies become negative mainly because of the thinness of the oceanic crust, while rise anomalies become positive mainly because of remanent magnetization concentrated over old spreading ridges, as advocated by RITZWOLLER and BENTLEY (1982).

As for the anomalies over East Antarctica, the most significant feature is a wedgelike pattern consisting of three positive anomalies over Enderby Land, Gamburtsev Subglacial Mountains and Wilkes Land. Other highs and lows are definitely related to geologic provinces, but the more comprehensive interpretation of their origin and pattern would require a reduced-to-pole representation of the anomalies and further geological and geophysical studies. 
The data used in this study were those supplied from NASA in 1980-81 to the Japanese MAGSAT Team (Naoshi Fukushima, Chairman) under the Statement of Work M-43. The authors are very grateful to Prof. N. Fukushima for his support to the present analysis, and useful suggestions for improving the manuscript. This study was originally a master thesis of J. Takenata, who thanks Prof. H. Kinoshita of Chiba University, Prof. K. Kaminuma of the National Institute of Polar Research and Dr. P. Wasilewski of NASA for their encouragements.

The compilation of ANOMANT tapes from MAGSAT CHRONFIN tapes using HITAC M260H was carried out at the Data Analysis Center of the National Institute of Polar Research, and the authors thank especially Messrs. H. Sakurai and K. Uchida. Geomagnetic $K_{\mathrm{p}}$ indices were made available from the World Data Center C-2 for Aurora.

\section{REFERENCES}

AKASOFU, S. I. and S. CHAPMAN, The ring current, geomagnetic disturbance, and the Van Allen radiation belts, J. Geophys. Res., 66, 1321-1350, 1961.

Briggs, I. C., Machine contouring using minimum curvature, Geophysics, 39, 39-48, 1974.

Drewry, D. J. (ed.), The bedrock surface of Antarctica. Antarctica; Glaciological and Geophysical Folio. Cambridge, Scott Polar Res. Inst., Sheet 3, 1983.

Frey, H., MAGSAT scalar anomaly distribution: The global perspective, Geophys. Res. Lett., 9, 277-280, 1982.

Grikurov, G. E., Geological World Atlas (1/10 000 000), Sheet 17, Antarctica, edited by Commission for the geological map of the world, International Geological Mapping Bureau, Paris, C.G.M.W.-Unesco, 1979.

Hiroi, Y., K. Shiraishi, Y. Motoyoshi, S. Kanisawa, K. Yanai, and K. KizaKi, Mode of occurrence, bulk chemical compositions, and mineral textures of ultramafic rocks in the Lützow-Holm Complex, East Antarctica, Mem. Natl Inst. Polar Res., Spec. Issue, 43, 62-84, 1986.

LANGEL, R. A., Near-earth magnetic disturbance in total field at high latitudes, 1. Summary of data from Ogo 2, 4, and 6, J. Geophys. Res., 79, 2363-2371, 1974a.

LANGEl, R. A., Near-earth magnetic disturbance in total field at high latitudes, 2. Interpretation of data from Ogo 2, 4, and 6, J. Geophys. Res., 79, 2373-2392, 1974b.

LAnGel, R. A. and R. H. Estes, A geomagnetic field spectrum, Geophys. Res. Lett., 9, 250-253, 1982.

LANGel, R. A. and R. H. Estes, The near-earth magnetic field at 1980 determined from Magsat data, $J$. Geophys. Res., 90, 2495-2509, 1985.

LAngel, R., J. Berbert, T. Jennings, and R. Horner, Magsat data processing; A report for investigators, NASA GSFC Technical Memorandum, TM82160, Nov. 1981.

Langel, R., G. Ousley, J. Berbert, J. Murphy, and M. Settle, The Magsat mission, Geophys. Res. Lett., 9, 243-245, 1982.

Masolov, V. N., R. G. Kurinin, and G. E. Grikurov, Crustal structures and tectonic significance of Antarctic rift zones (from geophysical evidence), Gondwana Five, edited by M. M. Cresswell and P. Vella, pp. 303-309, A. A. Balkema, Rotterdam, 1981.

MAYHEW, M. A., Inversion of satellite magnetic anomaly data, J. Geophys., 45, 119-128, 1979.

Moriwaki, K. and Y. Yoshida, Submarine topography of Lützow-Holm Bay, Antarctica, Mem. Natl Inst. Polar Res., Spec. Issue, 28, 247-258, 1983.

Nagata, T. and S. Kokubun, An additional geomagnetic daily variation field $\left(S_{\mathrm{q}}^{\mathrm{p}}\right.$-field $)$ in the polar region on geomagnetically quiet day, Rept. Ionos. Space Res. Japan, 16, 256-274, 1962.

Ritzwoller, M. H. and C. R. Bentley, Magsat magnetic anomalies over Antarctica and the surrounding oceans, Geophys. Res. Lett., 9, 285-288, 1982.

Ritzwoller, M. H. and C. R. Bentley, Magnetic anomalies over Antarctica measured from Magsat, in Antarctic Earth Science, edited by R. L. Oliver et al., pp. 504-507, Cambridge Univ. Press, Cambridge, 1983.

Segawa, J., T. Matsumoto, and K. Kaminuma, Brief topography in Antarctic region for reference for gravity anomaly chart, Appendix for Antarctic Special Map Series, No. 3, Natl Inst. Polar Res., Tokyo, 1984.

Shibuya, K. and Y. TAnAKa, An aeromagnetic survey over the Shirase glacier, Mem. Natl Inst. Polar Res., Spec. Issue, 28, 1-17, 1983. 
Shiraishi, K., Geology and petrology of Late Proterozoic metamorphic complexes in eastern Queen Maud Land, East Antarctic shield, D. Sc. Thesis, Hokkaido Univ., 246 pp., 1986.

Yanagisawa, M. and M. Kono, Magnetic anomaly maps obtained by means of the Mean Ionospheric Field correction J. Geomag. Geoelectr., 36, 417-441, 1984.

Yanagisawa, M. and M. Kono, Mean ionospheric field correction for Magsat data, J. Geophys. Res., 90, 2527-2536, 1985. 